\title{
Musculoskeletal Disorder (MSDs) and Rapid Upper Limb Assessment (RULA) Scoring Among Rubber Tappers
}

\author{
Meksawi $\mathrm{S}^{1}$, Tangtrakulwanich $\mathrm{B}^{2}$ and Chongsuvivatwong $\mathrm{V}^{3}$ \\ ${ }^{1}$ Faculty of Health and Sport Science, Thaksin University, Thailand \\ ${ }^{2}$ Department of Orthopaedic Surgery and Physical Medicine, Faculty of Medicine, Prince \\ of Songkla University, Thailand \\ ${ }^{3}$ Epidemiology Unit, Faculty of Medicine, Prince of Songkla University, Thailand
}

\section{Research Article}

Volume 2 Issue 4

Received Date: June 15, 2018

Published Date: June 29, 2018

DOI: $10.23880 /$ eoij-16000163

*Corresponding author: Supaporn Meksawi, Faculty of Health and Sport Science. Thaksin University, Phatthalung, Thailand, Email: smeksawi@yahoo.com

\section{Abstract}

Due to a large population at risk of MSDs in the rubber tapping occupation, this study aimed to survey the MSD problems on different parts of rubber tappers' bodies, and evaluate the RULA scoring system in terms of its pain prediction ability. 427 rubber tappers actively engaged in rubber tapping for at least 1 month, aged between 15-60 years, were recruited. Data were gathered using a questionnaire-based interview with an analog pain rating scale and a body discomfort chart. Video-based analysis of the various most common rubber tapping postures using the RULA method was also done. Factor analysis was used to group the correlated items of the RULA body part scores and pain scores from the relevant regions. Linear modeling was also performed to determine the ability of the various RULA factors to predict the associated pain scores. $52.9 \%$ of the rubber tappers reported current back pain, while pain at other bodily areas was uncommon $(2.1 \%$ 14.8\%). In contrast, the RULA scores did not indicate the back to have the highest risk. Factor analysis found the RULA scores could be grouped into 3 factors. Linear modeling demonstrated a significant association between back pain and the RULA factor involving the vertebra and upper arm. However, the RULA scores had a poor predictive ability concerning body pains of the rubber tappers (R-squared=0.08), and further studies on the causes of back pain are needed.

Keywords: Rubber Tappers; MSDs; RULA; Risk Assessment; Ergonomic; Pain Prediction

\section{Introduction}

Musculoskeletal disorders (MSDs) are often workrelated and can be a major health problem in many occupations. One such disorder is the "regional musculoskeletal disorder", which includes problems such as low back pain and upper and lower limb disorders. Health-related problems range from discomfort and general aches and pains to more serious medical conditions. Studies have found that the prevalence of MSDs varies in different occupations from 15-42\%. For example, farmers or agricultural workers have reported 


\section{Ergonomics International Journal}

the highest prevalences of lower back pain (LBP) than other occupations [1-5]. Risk factors of MSDs include physical, psychological, and socio-demographic aspects [6-8]. The physical ergonomic factors associated with MSDs, especially LBP, include non-neutral body postures, awkward postures, and highly repetitive work [9-12].

Rubber tapping is an important occupation in parts of Asia, especially in Thailand, Indonesia, Malaysia, India, and Sri Lanka, with a large number of workers (approximately 1.2 million workers in Southern Thailand). Rubber tapping is the process by which natural rubber is collected from the rubber trees. The rubber tapper uses a special sharp tapping knife to cut the tree bark along a downward $30^{\circ}$ degree left to right oblique curve that pens the latex vessels in the tree trunk and allows the sap to drain and be collected. The force of the stroke must be optimized to remove only a thin piece of the bark to preserve the health of tree yet allow the latex sap to flow freely enough to be collected in useful amounts. This work task often involves rubber tappers in ergonomically awkward activities, such as the repetitive cutting movement often repeated hundreds of times per day and awkward postures of the upper limbs, neck, trunk, and legs. Previous reports have found that MSDs are a major health problem among rubber tappers, especially low back pain (55\%) and carpal tunnel syndrome (19\%) [13]. The Rapid Upper Limb Assessment (RULA) is a favorable tool for evaluating ergonomic risk factors of work-related MSDs due to work posture, muscle use, and forces exerted on the upper arms, lower arms, neck, trunk, and legs [14]. As the RULA includes components from several body regions, it is reasonable to assume that some of these might be correlated in any given physically stressful activity. The collective or accumulative effect of various components may be associated with pain in different regions. An integrated examination of RULA components and their relationship with region-specific MSDs has never been undertaken, and this study was undertaken in rubber tappers as they have a number of potentially interrelated ergonomic problems and various MSDs, as an opportunity to use this task as a model to examine correlations among the components of RULA and their corrected with various body pains of rubber tappers.

\section{Materials and Methods}

\section{Study Design}

A cross-sectional survey for MSDs was conducted using face-to-face interviews and physical examinations, coordinated with a video-based analysis of the working postures of the tappers using the RULA method.

\section{Subjects}

This study was approved by the Ethics Committee of the Faculty of Medicine, Prince of Songkla University (SUB.EC 51/354-009). All of the subjects signed their formal consent form before data collection.

The subjects were Thai rubber tappers in Sawi district, Chumporn province in southern Thailand who had been employed in a rubber plantation for at least one month and were aged between 15 and 60 years. Subjects who had any history of major back, arm, and wrist trauma such as a motor vehicle accident, sports injury, fall from height, potential serious spinal condition or other specific back disorder were excluded.

\section{Sample Size}

Based on a previous study which reported a prevalence of low back pain among rubber tapers of $55 \%$, with a design effect of 1.2 , the required sample size, with an estimated non-response rate of $10 \%$, was 502 subjects.

\section{Sampling Procedure}

The names of 3,256 rubber tappers in the study area obtained from a pre-study survey were selected using systematic random sampling.

\section{Data Collection}

Data collection included interviews using a questionnaire, physical examination, and video recoding of the actual work of each subject for later video-based analysis of their working postures. The potential subjects were first screened for eligibility with a physical examination procedure adopted from the AHCPR Clinician Guideline 1994 [15]. The examination included general observation and a regional back examination, neurological screening, a straight-leg raising test, and a sitting knee extension test. After the physical examination, the body discomfort chart and analog pain rating scale were completed by all subjects. The items included the pattern and intensity of pain, if any, in any body region during the previous three months. On a separate occasion, the subjects were visited at their workplace in the rubber plantation and direct observations of the tapping process were made using a VDO recorder (SONY DCR-SR88), for later analysis using the RULA method.

\section{RULA Method}

The video clip taken during the rubber tapping task of each subject was later watched and the level of ergonomic risk evaluated by calculating a posture score for each 


\section{Ergonomics International Journal}

body parts through the RULA method. The posture scores of the upper arms, neck, and back ranged from 1 to 6 , the lower arms and wrist scores from 1 to 4 , and the leg scores from 1 to 2 . A score of 1 indicated the "best" or "most natural posture", while higher scores showed increasingly more unbalanced positions. The combined individual RULA body part scores of the upper arms, lower arms and wrist were gathered collectively as score A and those for the neck, trunk and legs as score B. Muscle use and force exerted in the rubber tapping posture were attributed scores of 1 and 0 respectively, because the actions were repeated over 4 times per minute with small loading; these scores were added to scores $\mathrm{A}$ and $\mathrm{B}$ to obtain scores $\mathrm{C}$ and $\mathrm{D}$, respectively. The combination of scores $\mathrm{C}$ and $\mathrm{D}$ gave a total score called grand score. Eventually the grand scores ranged from 1 to 7 . The RULA guideline indicates a low grand score of one or two means that the work posture is acceptable, while a grand score of 3 or 4 indicates further investigation and changes may be required. A grand score of 5 to 6 is a warning that prompts investigation and changes are required, and a grand score of 7 indicates immediately changes are required.

The reliability of the RULA system used in this study was assessed through evaluating inter-observer agreement between two independent raters. Good interassessor reliability (kappa $=0.86,0.83,0.9,0.86$, and 0.73 for arms, wrists, neck, trunk, and legs, respectively) were achieved.

\section{Statistical Analysis}

Descriptive statistics were used to summarize the general demographic data of the subjects and distribution of MSDs according to body region. Correlation coefficients among several RULA body part scores were computed. Factor analysis using the maximum likelihood method was done to group correlated items into underlying factors. A scree plot was used to choose the appropriate number of factors. To improve the model, orthogonal rotation was performed using the varimax rotation method. Factor loading and uniqueness of each item were used to identify the underlying factors of the various RULA items. The pain score of the corresponding body region of RULA elements was undergone in a similar fashion of analysis. Linear modeling was performed to determine the ability of the RULA scoring factors in predicting common regional pain. The final model was chosen based on having the lowest value of Akaike information criteria (AIC) (Cetin and Erar, 2002). R- square was used to judge the level of fitness of the model. Percent variance contributed by each independent variable was computed from analysis variance of the model. All the analyses were performed using R software version 2.9.0, and statistical significance was set at $<0.05$.

\section{Results}

\section{Demographic Data}

Of 502 randomly selected rubber tappers in the study area, $427(85.1 \%)$ agreed to participate in the study. The most common reason for refusing to participate was a perceived loss of privacy when recording the video of their working posture. Table 1 summarizes the demographic characteristics of the participants. Two third were male. Most were middle-aged with long working experience and a low level of background education. The prevalence of smoking was relatively high, especially among men. The average body mass index value was within the normal range.

\begin{tabular}{|l|c|}
\hline \multicolumn{1}{|c|}{ Characteristic } & N (\%) \\
\hline Sex & \\
\hline - Male & $285(66.7)$ \\
\hline - Female & $142(33.3)$ \\
\hline Age (mean \pm SD) yrs = 38.17 (9.2) & \\
\hline Years working (mean \pm SD) $=9.02(6.2)$ & \\
\hline Educational level & \\
\hline - Primary school & $300(70.2)$ \\
\hline - Secondary school & $69(16.2)$ \\
\hline - Post-secondary & $58(13.6)$ \\
\hline Current smoker & \\
\hline - Yes & $183(42.9)$ \\
\hline - No & $244(57.1)$ \\
\hline BMI (mean $\pm S D)=22.6(3.3)$ & \\
\hline
\end{tabular}

Table 1: Demographic data $(\mathrm{N}=427)$.

\section{MSDs and RULA Score in Various Body Regions}

Table 2 shows the distribution of pain scores on the tested body areas of the rubber tappers, and the proportion of corresponding full RULA scores. The mean and the median of the back pain scores, and the prevalence of having a pain score $>3$, were higher than the scores from the other regions. In contrast, however, the back was not identified by the RULA method as the region with the highest risk, as following the RULA method identified the postures of the legs, lower arms, and upper arms as more at risk. 


\section{Ergonomics International Journal}

\begin{tabular}{|l|c|c|c|}
\hline \multicolumn{1}{|c|}{ Body region } & Mean pain score (SD) & Percentage of pain scores $\geq \mathbf{3 ~ ( 9 5 \% C I )}$ & Mean RULA score/ full score \\
\hline Upper arms & $0.4(1.3)$ & $8.9(6.4-12.0)$ & $3.27 / 6$ \\
\hline Lower arms & $0.1(0.6)$ & $2.1(1.0-4.0)$ & $2.76 / 4$ \\
\hline Wrists & $0.1(0.6)$ & $2.3(1.1-4.3)$ & $1.88 / 4$ \\
\hline Neck & $0.1(0.8)$ & $3.0(1.6-5.2)$ & $2.90 / 6$ \\
\hline Back & $2.7(2.8)$ & $52.9(48.1-57.7)$ & $2.77 / 6$ \\
\hline Legs & $0.6(1.6)$ & $14.8(11.5-18.5)$ & $1.83 / 2$ \\
\hline
\end{tabular}

Table 2: The distribution of pain scores on various body regions, and the corresponding RULA full scores ( $N=427)$.

\begin{tabular}{|l|c|c|}
\hline \multicolumn{1}{|c|}{ Location of pain } & frequency & percent \\
\hline None & 158 & 37.0 \\
\hline Back & 149 & 34.9 \\
\hline Back+legs & 40 & 9.4 \\
\hline Back+upper arm & 24 & 5.6 \\
\hline Legs & 14 & 3.3 \\
\hline Upper arm & 14 & 3.3 \\
\hline Back+neck & 9 & 2.1 \\
\hline Legs+lower arms & 9 & 2.1 \\
\hline Wrists & 6 & 1.4 \\
\hline Back+neck+wrists & 4 & 0.9 \\
\hline
\end{tabular}

Table 3: Pattern of pain distribution.

Table 3 shows the overall pattern of pain distribution. Over a third of the participants reported no MSDs, while back pain with or without another local pain occurred was reported in over half (52\%) of the participants.

overall, pains at other regions were relatively rare and often isolated.

\section{Correlation Matrix and Factor Analysis of RULA Scores and Pain Scores of 6 Body Regions}

Six elements of the RULA scores had an important correlation, such as coefficients in neck-trunk (0.55), lower arm-wrist (0.40), leg-upper arm (0.35), leg-lower arm (0.34), and neck-upper arm (0.30). Figure 2 contains scree plots of RULA (2a) and pain scores (2b) The scree plot of the RULA body part scores shows an elbow shape, whereas that of the pain scores does not, suggesting that the RULA items may be grouped into factors, but not the pain score items. The number of RULA items was judged to be 3 factors, as the point has an eigen value close to 1 , the 3 factors could explain as much as $62 \%$ of variance of the RULA items.

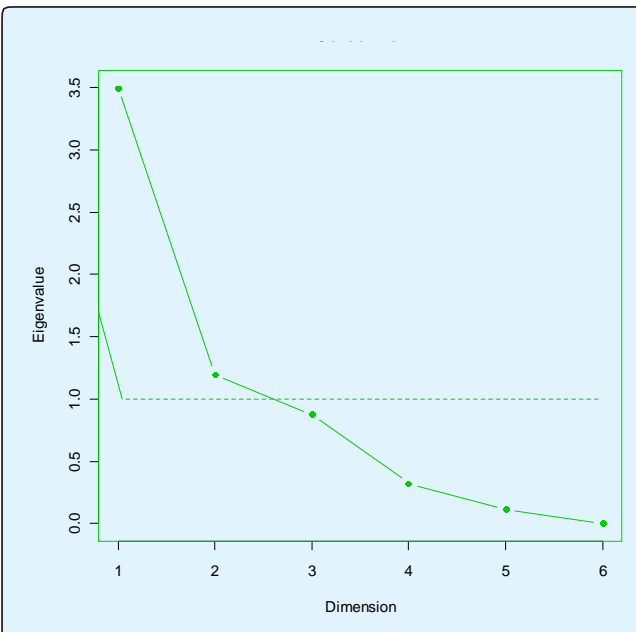

$2 a$.

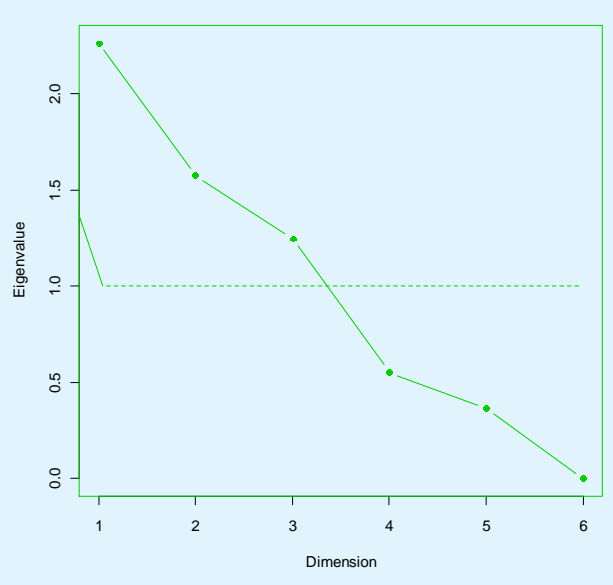

$2 \mathrm{~b}$.

Figure 2: The scree plots of the RULA body part scores (2a) and the pain scores (2b).

After rotation, the factor loading on elements of the RULA scores, using a cutoff point of $>0.4$, is shown in Table 4. Factor 1 contributes substantially to the scores of the lower arms and wrists, factor 2 to the upper arms, neck, and trunk scores, and factor 3 to the legs score alone. Factor 1 could be named as the "lower arm-wrist factor", factor 2 as the "vertebrae and upper arm factor", and 


\section{Ergonomics International Journal}

factor 3 as the "leg factor". Correlation among these factors was less than 0.08

\begin{tabular}{|l|c|c|c|}
\hline \multirow{2}{*}{ RULA body part score } & \multicolumn{3}{c|}{ Factor } \\
\cline { 2 - 4 } & 1 & 2 & 3 \\
\hline Upper arm score & 0.24 & 0.44 & - \\
\hline Lower arm score & 0.82 & - & - \\
\hline Wrist score & 0.48 & - & 0.12 \\
\hline Neck score & -0.20 & 0.81 & - \\
\hline Trunk score & -0.47 & 0.57 & 0.31 \\
\hline Legs score & 0.15 & - & 0.70 \\
\hline
\end{tabular}

Table 4: Factor loading for three-factor analyses of RULA body part scores.

For the correlation matrix of the pain scores, the highest correlation coefficient was found between the pain scores of the legs and lower arms (0.34), followed by the wrists and neck $(0.29)$. The remaining correlation coefficients were below 0.12 . Factor analysis of the pain scores among the regions was not useful, due to the uniqueness of most items ( 4 in 6 items) were high $(>0.6)$.

\section{Correlation between Pain and RULA Score}

The correlation between pain and the raw RULA body part scores was highest between the trunk RULA scores and back pain scores (0.34), followed by the neck RULA scores and back pain scores (0.24). The remaining coefficients were below 0.12 . When the RULA factors as identified through factor analysis were used instead of the raw scores, a small correlation coefficient (0.23) was found between the vertebrae and upper arms factor and back pain scores. The remaining correlation coefficients were below 0.1 .

\section{Contribution of RULA Score in Predicting Back Pain}

As back pain is the most serious MSDs in this occupational group, it was chosen as the outcome variable. The trunk RULA factor score as identified through RULA factor analysis (vertebrae and upper arms factor) was used to predict the intensity of back pain. The other variables used for predicting back pain were age, height, weight, worked years, number of trees tapped per day, and sleep hours per night. Table 5 shows the best-fit linear model with an AIC of 828.57. The AIC slightly increased to 854.3 when individual RULA items of RULA were added to the model. This indicates that in our model, the factor scores had a better predicting capacity than the individual RULA items did. However, from analysis of variance of this model, only $5.4 \%$ of the total sum of the square of the back pain level was due to variation in this RULA factor and R-squared was only $8 \%$. Thus the RULA score had a poor outcome in terms of predicting the degree of back pain among the rubber tappers.

\begin{tabular}{|l|c|c|c|c|}
\hline \multicolumn{1}{|c|}{ Variable } & coeff $\mathbf{( 9 5 \%} \mathbf{~ C I})$ & Std. error & p-value & \% variance explained \\
\hline Height & $0.02(0.00,0.04)$ & 0.01 & 0.12 & 0.54 \\
\hline Sleep hours per day & $-0.31(-0.51,-0.11)$ & 0.13 & $0.002^{*}$ & 2.1 \\
\hline $\begin{array}{l}\text { Vertebrae and } \\
\text { upper arms factor }\end{array}$ & $0.59(0.33,0.84)$ & 0.10 & $<0.001^{*}$ & 5.42 \\
\hline R-squared & 0.08 & & & \\
\hline
\end{tabular}

Table 5: Factors associated with back pain.

\section{Discussion}

Among the rubber tappers in the current study, back pain was the most common MSD complaint, but the RULA body parts scores did not indicate the back as the region with the highest risk. The items of the RULA body part scores were inter-correlated and could be grouped into three factors. The pain scores of the corresponding parts were not well correlated and could not be grouped as factors. The RULA factor of the vertebrae and upper arms as identified from factor analysis was the most important predictor for back pain, but the prediction ability was rather low.
Originally, McAtamney and Corlett [14] first devised the RULA system for assistance in assessing ergonomic problems among operators of visual display units (VDUs). Since then it has been used for many studies, such as computer users overall, truck drivers, and press workers [17-19]. Most of these studies have found a positive association between pain and RULA body parts scores, although there have been some discrepancies, such as a recent study on pharmacy packaging workers, in which RULA failed to predict pain, similar to our study [20].

The correlation of the RULA score items in our study could possibly be explained by adjacency of the regions, such as neck-trunk, lower arms-wrists, and neck-upper 


\section{Ergonomics International Journal}

arms. However, the RULA score of the legs was also correlated with the distant upper arms and lower arms, but not the legs-trunk. This distant correlation is probably specific to the rubber tapping task, as a simultaneous awkward position of both legs and upper arms is necessary while tapping a tree at a high level, when the legs must cross each other while the upper arms are abducted up to $46^{\circ}-90^{\circ}$ and the elbows are flexed about $60^{\circ}-100^{\circ}$. Low inter-correlation of pain scores in the body regions would likely indicate that the pains at these other parts are not generally linked to one another.

Our study revealed a small degree of pain prediction ability with the RULA factor of the vertebrae and upper arms, suggesting that back pain in rubber tappers may be attributable to other factors. Back pain is known to be associated with not only physical work, but also psychosocial and individual factor [6-8]. The exact cause or causes of back pain among rubber tapper needs further investigation.

\section{Strengths and Limitations}

To our knowledge, this is probably the largest to-date community-based ergonomic survey among rubber tappers, and featured a high response rate (85\%). Using factor analysis, the nature of RULA and pain distribution could be better examined. However, the working postures and work tasks of rubber tappers are different from other occupational tasks, and thus our results are not likely highly generalizable.

\section{Conclusion}

Lacking ability of RULA in predicting back pain indicated further scientific investigation of this very common occupation problem of rubber tapper.

\section{Acknowledgment}

Special thanks are owed to all participants in Sawi district, Chumphon province. This study was financially supported by the Thailand Research Fund.

\section{References}

1. Hoogendoorn WE, van Poppel MN, Bongers PM, Koes BW, Bouter LM (1999) Physical load during work and leisure time as risk factors for back pain. Scand J Work Environ Health 25(5): 387-403.

2. Punnett L, Prüss-Utün A, Nelson DI, Fingerhut MA, Leigh J, et al. (2005) Estimating the global burden of low back pain attributable to combined occupational exposures. Am J Ind Med 48(6): 459-469.

3. Holmberg S, Thelin A, Stiernstrom E, Svardsudd K (2003) The impact of physical work exposure on musculoskeletal symptoms among farmers and rural non-farmers. Ann Agric Environ Med 10(2): 179-184.

4. Park H, Sprince NL, Whitten PS, Burmeister LF, Zwerling C (2001) Risk factors for back pain among male farmers: analysis of Iowa Farm Family Health and Hazard Surveillance Study. Am J Ind Med 40(6): 646-654.

5. Rosecrance J, Rodgers G, Merlino L (2006) Low back pain and musculoskeletal symptoms among Kansas farmers. Am J Ind Med 49(7): 547-556.

6. Bongers PM, de Winter CR, Kompier MA, Hildebrandt VH (1993) Psychosocial factors at work and musculoskeletal disease. Scand J Work Environ Health 19(5): 297-312.

7. Devereux JJ, Buckle PW, Vlachonikolis IG (1999) Interactions between physical and psychosocial risk factors at work increase the risk of back disorders: an epidemiological approach. Occup Environ Med 56(5): 343-353.

8. Devereux JJ, Vlachonikolis IG, Buckle PW (2002) Epidemiological study to investigate potential interaction between physical and psychosocial factors at work that may increase the risk of symptoms of musculoskeletal disorder of the neck and upper limb. Occup Environ Med 59(4): 269-277.

9. Burdorf A, Naaktgeboren B, de Groot HC (1993) Occupational risk factors for low back pain among sedentary workers. J Occup Med 35(12): 1213-1220.

10. Lee P, Helewa A, Goldsmith $\mathrm{CH}$, Smythe HA, Stitt LW (2001) Low back pain: prevalence and risk factors in an industrial setting. J Rheumatol 28(2): 346-351.

11. Juul-Kristensen B, Jensen C (2005) Self-reported workplace related ergonomic conditions as prognostic factors for musculoskeletal symptoms: the "BIT" follow up study on office workers. Occup Environ Med 62(3): 188-194.

12. Andersen JH, Haahr JP, Frost P (2007) Risk factors for more severe regional musculoskeletal symptoms: a two-year prospective study of a general working population. Arthritis Rheum 56(4): 1355-1364. 


\section{Ergonomics International Journal}

13. Bensaard N, Tuntiseranee P, Anuntaseree S (2004) Work conditions and prevalence of musculoskeletal pain among para-rubber planters: a case study in Tambon Nakleua, Kantang District, Trang Province. Songkla Med J 22(2): 101-110.

14. Mc Atamney L, Nigel Corlett E (1993) RULA: a survey method for the investigation of work-related upper limb disorders. Appl Ergon 24(2): 91-99.

15. Chou R, Qaseem A, Snow V, Casey D, Cross JT, et al. (2007) Diagnosis and treatment of low back pain: a joint clinical practice guideline from the American College of Physicians and the American Pain Society. Ann Intern Med 147(7): 478-491.

16. Cetin MC, Erar A (2002) Variable selection with Akaike Information Criteria: a comparative study. HJMS 31: 89-97.
17. Cook CJ, Kothiyal K (1998) Influence of mouse position on muscular activity in the neck, shoulder and arm in computer users. Appl Ergon 29(6): 439443.

18. Massaccesi M, Pagnotta A, Soccetti A, Masali M, Masiero C, et al. (2003) Investigation of work-related disorders in truck drivers using RULA method. Appl Ergon 34(4): 303-307.

19. Pourmahabadian M, Azam K (2006) Evaluation of risk factors associated with work-related musculoskeletal disorders of upper limbs extremity among press workers. Pak J Med Sci 22(4): 379-384.

20. Varmazyar S, Varyani AS, Zeidi IM, Hashemi HJ (2009) Evaluation working posture and musculoskeletal disorders prevalence in pharmacy packaging workers. EJSR 29(1): 82-88. 